\title{
Regulating Myoblast Phenotype Through Controlled Gel Stiffness and Degradation
}

\author{
TANYARUT BOONTHEEKUL, Ph.D., ${ }^{1,3}$ ELLIOTT E. HILL, Ph.D., \\ HYUN-JOON KONG, Ph.D., ${ }^{3}$ and DAVID J. MOONEY, Ph.D. ${ }^{3}$
}

\begin{abstract}
Mechanical stiffness and degradability are important material parameters in tissue engineering. The aim of this study was to address the hypothesis that these variables regulate the function of myoblasts cultured in 2-D and 3-D microenvironments. Development of cell-interactive alginate gels with tunable degradation rates and mechanical stiffness was established by a combination of partial oxidation and bimodal molecular weight distribution. Higher gel mechanical properties (13 to $45 \mathrm{kPa})$ increased myoblast adhesion, proliferation, and differentiation in a 2-D cell culture model. Primary mouse myoblasts were more highly responsive to this cue than the $\mathrm{C2C12}$ myoblast cell line. Myoblasts were then encapsulated in gels varying in degradation rate to simultaneously investigate the effect of degradation and subsequent reduction of mechanical properties on cells in a 3-D environment. $\mathrm{C2C12}$ cells in more rapidly degrading gels exhibited lower proliferation, as they exited the cell cycle to differentiate, compared to those in nondegradable gels. In contrast, mouse primary myoblasts illustrated significantly higher proliferation in degradable gels than in nondegradable gels, and exhibited minimal differentiation in either type of gel. Altogether, these studies suggest that a critical balance between material degradation rate and mechanical properties may be required to regulate formation of engineered skeletal muscle tissue, and that results obtained with the $\mathrm{C2C12}$ cell line may not be predictive of the response of primary myoblasts to environmental cues. The principles delineated in these studies may be useful to tailor smart biomaterials that can be applied to many other polymeric systems and tissue types.
\end{abstract}

\section{INTRODUCTION}

B IOMATERIALS TYPICALLY PLAY CRUCIAL ROLES in regenerative medicine and tissue engineering. In these applications, the materials support and bioactively interact with cells to control their function and spatially and temporally guide the process of tissue regeneration. ${ }^{1}$ Substrate stiffness and material degradation rate are the essential parameters in designing these materials. The mechanical compliance of biomaterials strongly regulates the gene expression of a variety of anchorage-dependent cells, including myoblasts. ${ }^{2-5}$ Conversely, cells can apply varying magnitudes of forces to these materials, and this "inside-out" signaling through the interactions between the cytoskeleton and the extracellular matrix (ECM) may change the ECM and the behavior of neighboring cells and tissues. ${ }^{5,6}$ Further, materials are often designed to degrade over time to provide space for new tissue formation. During the degradation process, material properties (e.g., mechanical stiffness) are altered, and this also could subsequently regulate cell proliferation, differentiation, and matrix deposition. Understanding the roles of biomaterials and their degradation is likely crucial for longterm success in tissue engineering. ${ }^{7}$ However, few studies exist that illustrate the direct relationship between material degradation rate and tissue formation, and these are in the areas of bone and cartilage engineering. ${ }^{8-10}$ 
Skeletal muscle tissue engineering holds promise for the treatment of a variety of muscle diseases (e.g., muscular dystrophy, spinal muscular dystrophy) or for the replacement of muscle lost as a result of trauma or reconstructive surgery. ${ }^{11}$ The process of new muscle formation requires that quiescent mononucleated muscle precursor cells become activated, proliferate, differentiate, and fuse together to form multinucleated myotubes. ${ }^{12}$ Proliferation and differentiation of skeletal myoblasts are mutually exclusive events and are governed by the upregulation of basic helix-loop-helix transcriptional activators of the myogenic regulatory factors (MRF). Proliferative MyoD and Myf5 positive cells are termed myoblasts. These proliferating myoblasts must withdraw from the cell cycle to become terminally differentiated myocytes that express late MRFs, myogenin, and MRF4. The cells subsequently express muscle structural protein myosin heavy chain (MHC) and muscle creatine kinase (MCK), and fuse to form multinucleated myofibers. ${ }^{13,14}$ Several distinct approaches are currently being investigated to therapeutically mediate the muscle regenerative process, including injection of growth factors, ${ }^{15}$ gene therapy, ${ }^{16}$ and the delivery of exogenous cells. ${ }^{17}$ In the latest approach, several polymeric carriers have been utilized to provide an artificial matrix for cell delivery, or a combination of cell, matrix, and growth factor delivery, to increase regeneration, rather than a direct injection of cell suspension. These materials include collagen gel, ${ }^{18}$ fibrin gel, ${ }^{19}$ polyglycolic acid mesh, ${ }^{20}$ and macroporous alginate scaffold. ${ }^{21}$

This study addressed the hypothesis that stiffness and degradation rate of scaffolding materials would regulate skeletal muscle cell adhesion, proliferation, and differentiation. This hypothesis was tested by examining first the effect of stiffness on skeletal muscle cells in standard 2-D cell cultures, and then the effect of bulk degradation with subsequent reduction of stiffness on cells in 3-D environments. Two types of skeletal muscle cells were employed in this study: $\mathrm{C} 2 \mathrm{C} 12$ cells and isolated primary myoblasts. The $\mathrm{C} 2 \mathrm{C} 12$ cells were originally derived from mouse myoblasts, and this transformed cell line has been widely used in studies of muscle biology and regeneration. ${ }^{11}$ However, cell lines typically lose some sensitivity to environmental cues, specifically those related to adhesion. To address this concern, experiments were also performed with primary myoblasts derived from mice in order to most closely approximate normal myogenesis. Alginate hydrogels were utilized as the adhesion substrate in these studies. Alginate is a naturally derived polysaccharide composed of linearly assembled (1-4)-linked $\beta$-mannuronic acid (M) and $\alpha$-guluronic acid $(\mathrm{G})$ monomers. Alginate gels are formed when blocks of G-monomers and divalent cation (e.g., $\mathrm{Ca}^{2+}$ ) interact to form ionic bridges between different polymer chains. ${ }^{22} \mathrm{Al}-$ ginate gels are considered biocompatible and have been used to transplant cells in a variety of applications. ${ }^{23,24}$ Cell adhesion to these gels can be promoted by incorporation of immobilized cell adhesion peptides (e.g. $\mathrm{G}_{4}$ RGDSP). ${ }^{25,26}$
Degradation can be manipulated in several ways, including partial oxidation of the polymer to allow hydrolytic breakdown ${ }^{27}$ utilization of bimodal molecular weight distribution to fabricate gels, ${ }^{28,29}$ or a combination of both approaches. ${ }^{30}$

\section{MATERIALS AND METHODS}

\section{Material chemistry}

MVG sodium alginate powder rich in GG-blocks (Pronova, Norway, $\mathrm{M}_{\mathrm{w}}=2.7 \times 10^{5} \mathrm{~g} / \mathrm{mol}$ ) was used as the high molecular weight component (abbreviated as HMW) to form gels. Low molecular weight alginate $\left(\mathrm{M}_{\mathrm{w}}=5.3 \times 10^{4}\right.$ $\mathrm{g} / \mathrm{mol}$, abbreviated as LMW) was obtained by gamma $(\gamma)$ irradiating HMW with a cobalt-60 source for 4 hours at a $\gamma$-dose of 5.0 Mrad (Phoenix Lab, University of Michigan), as specified by Kong et al. ${ }^{28}$ One percent of the sugar residues in both LMW and HMW were partially oxidized by reacting with sodium periodate to create hydrolytically labile bonds in the polysaccharide. ${ }^{30}$ Briefly, alginates were diluted to $1 \%$ $\mathrm{w} / \mathrm{v}$ in $\mathrm{dd} \mathrm{H}_{2} \mathrm{O}$, and sodium periodate $(21.6 \mathrm{mg} / \mathrm{g}$ alginate, Sigma Aldrich, St. Louis, MO) was added. The reaction was maintained in the dark for 19 hours and was subsequently stopped by adding an equimolar amount of ethylene glycol (Fisher Scientific, Pittsburgh, PA). The solution was then dialyzed (MWCO 1000, Spectra/Por ${ }^{\circledR}$, Fisher Scientific), filtered, and lyophilized. Further, alginates were covalently conjugated with a $\mathrm{G}_{4}$ RGDSP oligopeptide (Commonwealth Biotechnology, Richmond, VA) at an average density of $3.4 \mathrm{mM}$ peptide/mole of alginate monomer, so as to promote specific cell-matrix interactions, using carbodiimide chemistry as described by Rowley et $a{ }^{26}$ Finally, the modified alginates were reconstituted in calcium-free Dulbecco's modified Eagle's medium (DMEM, Invitrogen, Carlsbad, CA) to obtain a $2 \% \mathrm{w} / \mathrm{v}$ solution prior to gelation.

\section{Primary myoblast isolation and cell culture}

The $\mathrm{C} 2 \mathrm{C} 12$ cell line was obtained from the American Type Culture Collection (ATCC, Manassa, VA). Primary myoblasts were isolated from 4- to 6-week-old C57BL/6 mice hind limb skeletal musculature. Following euthanization, the tibialis muscle of the hind limb was excised, finely minced, and transferred to dissociation medium (DMEM with $5 \%$ trypsin, $0.075 \% \mathrm{w} / \mathrm{v}$ of collagenase type 4 ) for 60 minutes at $37^{\circ} \mathrm{C}$ in a $5 \% \mathrm{CO}_{2}$ incubator with agitation. Dissociated cells were subsequently collected by filtering through a $40 \mu \mathrm{m}$ nylon mesh that removed connective tissue and adipocytes. Cells were centrifuged at $1,100 \mathrm{rpm}$ for 5 minutes, resuspended, and cultured for 72 hours with growth medium (DMEM supplemented with $10 \%$ fetal bovine serum (FBS), $1 \%$ penicillin/streptomycin) before media change. After reaching $80 \%$ confluence (about 7 days), cells were purified by overlaying them on Percoll gradient columns, consisting of 20\%, 30\%, and 50\% Percoll diluted 
in DMEM, F-12, and phosphate buffered saline (PBS), respectively. Cells were collected at the interface of $20 / 30 \%$ Percoll after centrifugation for 20 minutes at $1,600 \mathrm{rpm}$. Both the $\mathrm{C} 2 \mathrm{C} 12$ cell line and the purified primary myoblasts were typically cultured in growth medium. At specific times in cultures, the medium of $\mathrm{C} 2 \mathrm{C} 12$ cells was changed to differentiation medium (DMEM supplemented with $10 \%$ horse serum (HS), $1 \%$ penicillin/streptomycin).

\section{Hydrogel formation and cell seeding}

In 2-D cell culture studies, different gel types were used. Gels composed solely of a single type of alginate chain were termed unary gels, while those composed of two types of chains of differing MW were termed binary gels. Three alginate gel conditions were used: (1) partially oxidized binary gels $(\mathrm{LMW}: \mathrm{HMW}=1: 1)$ with 3 weeks preincubation $(\mathrm{E}=$ $1 \mathrm{kPa}),(2)$ partially oxidized binary gels without preincubation $(\mathrm{E}=13 \mathrm{kPa})$, and (3) nonoxidized unary gels without preincubation $(\mathrm{E}=45 \mathrm{kPa})$. To create these gels, the alginate solution was mixed with calcium sulphate $\left(\mathrm{CaSO}_{4}\right)$ slurry (8.4 $\mathrm{g} \mathrm{CaSO}_{4}$ in $40 \mathrm{~mL} \mathrm{H}_{2} \mathrm{O}$ ) through syringe connectors at the ratio of $40 \mu \mathrm{L} \mathrm{CaSO}_{4}$ solution to $1 \mathrm{~mL}$ alginate solution. The mixtures were allowed to gel for 30 minutes between two glass plates separated by a $1 \mathrm{~mm}$ spacer. Gel disks were punched out using a $11.7 \mathrm{~mm}$ puncher. Partially oxidized binary gels were incubated with DMEM for 3 weeks with the medium changed twice a week. Cells (either $\mathrm{C} 2 \mathrm{C} 12$ or purified primary myoblasts) were seeded onto these gels at the density of 7,500 cells $/ \mathrm{cm}^{2}$ in non-tissue culture treated 24well plates. At 4 and 8 hours postseeding (for $\mathrm{C} 2 \mathrm{C} 12$ cells and primary myoblasts, respectively), nonadherent cells were removed and the alginate gels were transferred to new plates. Alginate disks (at least four samples per condition per time point) were harvested at various time points to assess cell morphology, adhesion, proliferation, and differentiation. The stiffness of the gels was determined by measuring the compressive elastic modulus (E) with a mechanical tester (MTS Bionix 100, MTS Ltd., Gloucester, UK) ${ }^{30}$

$\mathrm{C} 2 \mathrm{C} 12$ and primary myoblasts were also encapsulated in different types of alginate gels. The $\mathrm{C} 2 \mathrm{C} 12\left(30 \times 10^{6}\right.$ cells $/ \mathrm{mL}$ gel) were encapsulated in (1) partially oxidized binary (LMW: HMW $=1: 1$ ) gels, (2) partially oxidized unary (HMW) gels, and (3) nonoxidized unary (HMW) gels. Primary cells (10× $10^{6}$ cells/mL gel) were encapsulated in gel types 1 and 3 . For both cell types, cells were harvested from culture plates, counted using a Coulter counter (Coulter Electronics, Buckinghamshire, UK), and transferred to a syringe to centrifuge. Cell pellets were subsequently mixed with alginate solutions through syringe connectors. The cell/alginate mixtures were then ionically cross-linked by mixing with $\mathrm{CaSO}_{4}$ slurry ( $8.4 \mathrm{~g} \mathrm{CaSO}_{4}$ in $40 \mathrm{~mL} \mathrm{H}_{2} \mathrm{O}$ ) at the ratio of $40 \mu \mathrm{L} \mathrm{CaSO}_{4}$ solution to $1 \mathrm{~mL}$ alginate solution. The mixtures were allowed to gel for 30 minutes between two glass plates separated by a $1 \mathrm{~mm}$ spacer. Gel disks encapsulating the cells were punched out using a $4.5 \mathrm{~mm}$ puncher, placed in a spinner flask with growth medium, and cultured in a $\mathrm{CO}_{2}$ incubator for 21 days. Growth medium was changed every 2 days until day 15 , when the cells were switched to differentiation medium. At particular time points, three to six samples per condition were collected to assess viability, proliferation, morphology, and protein expression.

\section{Biological assays}

Immunohistochemistry. To characterize primary cell populations after isolation and Percoll purification, cells were plated on sterile coverslips overnight, fixed in $3.7 \%$ formaldehyde for 10 minutes, permeabilized with a solution of $0.5 \%$ Triton X-100 (Sigma, St. Louis, MO), and incubated in $5 \%$ dry milk in PBS for 10 minutes. Cells were stained using an anti-desmin monoclonal antibody (1:100, Chemicon, Temecula, CA), followed by immunofluorescent FITC secondary antibody (1:1,000, Jackson Labs, PA) and Hoechst nuclear dye (1:1,000, Molecular Probes, Eugene, OR). The coverslips were extensively rinsed between steps, then mounted on glass slides with mounting medium, and sealed with clear nail polish. Slides were imaged with a Nikon Eclipse E-800 fluorescent light microscope.

Myoblasts encapsulated within the gels were visualized by staining the actin cytoskeleton on day 7. Gels were rinsed with PBS, fixed in $3.7 \%$ formaldehyde solution in PBS for 15 minutes, then permeabilized with a solution of $0.5 \%$ Triton X-100, and incubated in 5\% dry milk in PBS for 15 minutes. Oregon Green Phalloidin (Molecular Probes) was diluted to 5 units $/ \mathrm{mL}$ in PBS and $1.5 \mathrm{~mL}$ was used to stain each gel. After extensive rinses in $0.1 \%$ Triton X-100 in PBS, the gels were mounted onto coverslips and visualized with a BioRad radiance 200 confocal system.

Cell viability and proliferation assay. Cell number was directly analyzed in 2-D cell cultures on days 0,2 , 4, and 7 by placing the samples in $1 \mathrm{~mL}$ of $0.25 \mathrm{M}$ trypsin for 5 minutes at $37^{\circ} \mathrm{C}$, to which $9 \mathrm{~mL}$ of $50 \mathrm{mM}$ EDTA in PBS ( $\mathrm{pH}$ 7.4) was subsequently added, and incubating for 30 minutes in order to dissolve the gels. Cell number was determined using a Coulter counter.

In cell encapsulation experiments, cell-alginate constructs were treated with 3-(4,5-Dimethylthiazol-2-yl)-2, 5-diphenyltetrazolium bromide (MTT) at 0 hour, and days 1 , 7,14 , and 18 postgelling to assess cell viability. Each sample was harvested, transferred to 24-well nontreated plates with $1 \mathrm{~mL}$ of DMEM, and incubated with $100 \mu \mathrm{L}$ of tetrazolium component in MTT solution (ATCC) for 4 hours at $37^{\circ} \mathrm{C}$. Viable cells were assessed by the reduction of an MTT tetrazolium component into an insoluble dark purple formazan produced by mitochondria of viable cells. Cell proliferation was assessed by measuring $\left[{ }^{3} \mathrm{H}\right]$ thymidine incorporation on days 5,10 , and 15. Cell-alginate constructs were incubated in medium containing $1 \mu \mathrm{Ci}$ of thymidine [methyl- ${ }^{3} \mathrm{H}$ ] 
(PerkinElmer, NET-027Z, Waltham, MA) for 24 hours. Gels were collected and rinsed with PBS twice to remove unincorporated thymidine, and dissolved with $50 \mathrm{mM}$ EDTA in PBS for 30 minutes. Following centrifugation, cell pellets were rinsed with PBS and incubated with 5\% trichloroacetic acid (TCA) in PBS for 30 minutes. Cells were lysed with $10.25 \mathrm{~N} \mathrm{NaOH}$, diluted with scintillation liquid, and $\left[{ }^{3} \mathrm{H}\right]$ thymidine incorporation was determined using a scintillation counter (PerkinElmer). Thymidine incorporation of adherent myoblasts on 2-D gels was used as a positive control, and gels without cells were used as a negative control. Cell number was also counted using a Coulter counter after the dissolution of the gels with $50 \mathrm{mM}$ EDTA in PBS on days 5, 10, and 15, for cell encapsulation experiments.

Western blot analysis. The expression of proteins indicative of myoblast differentiation (myogenin and MHC) was evaluated by standard Western blotting. Gels with encapsulated cells were harvested on days 5,12 , and 19, rinsed with PBS, and dissolved with $50 \mathrm{mM}$ EDTA in PBS. Following centrifugation, supernatants were removed. Cytoplasmic proteins were extracted by incubating the cells with passive lysis buffer (PLB, Promega, Madison, WI). To ascertain equal loading of gels, the amount of protein in each sample was measured using BioRad protein assay reagent. Protein samples were loaded under denaturing conditions into precast $7.5 \%$ (for MHC expression) or 10-20\% (for myogenin) Tris$\mathrm{HCl}$ polyacrylamide (PA) gels and electrophoresced at $200 \mathrm{~V}$ for 42 minutes. Proteins were transferred to polyvinylidene fluoride (PVDF) membrane. Membranes were blocked with $5 \%$ bovine serum albumin (BSA) in Tris buffer with $0.1 \%$ Tween-20 and incubated with primary antibodies (myogenin [Santa Cruz Biotechnology, Santa Cruz, CA], or MHC [Iowa Hybridoma, Iowa City, IA]), followed by secondary antimouse IgG conjugated to horseradish peroxidase (BioRad, Hercules, CA). After extensive washes, proteins were detected by using enhanced chemiluminescence (ECL, Amersham Pharmacia, Buckinghamshire, UK) and visualized by exposure to Hyperfilm.

Determination of muscle creatine kinase activity. The activity of MCK was determined by using a creatine kinase kit (Pointe Scientific, Canton, MI). The reaction was maintained at $37^{\circ} \mathrm{C}$, and the rate of NADH formation was measured at $340 \mathrm{~nm}$ with a Bio-Tek plate reader. MCK activity of each sample was normalized by DNA quantity. To perform this analysis, the pellet fraction of cell lysates - collected on days 1, 2, and 4 for C2C12 cells, or on days 1, 3, 4 for primary myoblasts in 2-D studies, and on days 1, 5, 8, 11, and 14 for 3-D culture-was obtained by centrifugation, Caron's lysis buffer (CLB) was added to the pellet, and the mixture was sonicated for 6-8 seconds. This treatment disintegrates the cell nuclei and liberates and fragments the DNA. Incubation of the solution with a Hoechst dye solution allows the amount of DNA to be quantified using a fluorometer.

\section{RESULTS}

The effect of substrate stiffness on myoblast adhesion, proliferation, and differentiation was first examined by culturing the $\mathrm{C} 2 \mathrm{C} 12$ cells and isolated primary myoblasts on gels of varying stiffness (standard 2-D cell cultures). The 3-D cell culture studies then addressed the hypothesis that controlling the degradation rate of the scaffolding material would regulate the phenotype of skeletal muscle cells. Cells were encapsulated in three types of alginate hydrogels in which the degradation rate was varied by combining a low degree of partial alginate polymer oxidation and a bimodal molecular weight distribution: (1) partially oxidized binary gels (fastest degradation rate, compressive modulus decreased to $8 \%$ of initial value by 2 weeks), (2) partially oxidized unary gels (intermediate degradation rate, compressive modulus decreased to $25 \%$ of initial value by 2 weeks), and (3) nonoxidized unary gels (slowest degradation rate, compressive modulus decreased to $50 \%$ of initial value by 2 weeks). The degradation behavior of these gels was previously described. ${ }^{30}$ The primary cells were a homogeneous population in terms of morphology and desmin staining. Over $90 \%$ of the purified primary cell population used in the study was positive for desmin, an intermediate filament expressed during skeletal muscle development (Fig. 1). ${ }^{31}$ Approximately 600,000 purified cells per gram of tissue mass were obtained.

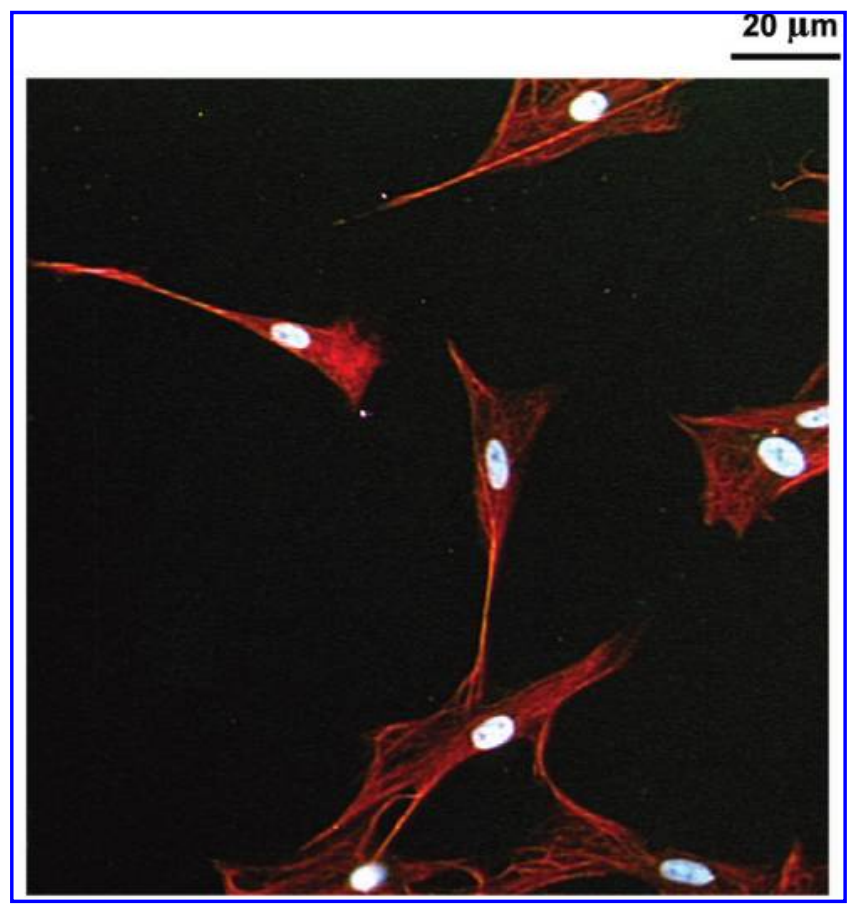

FIG. 1. Primary myoblast isolation. Upon purification, the vast majority of cells showed positive staining for desmin (red). Cells were counterstained with Hoechst dye to highlight cell nuclei (light blue). Color images available online at www.liebertpub.com/ten. 


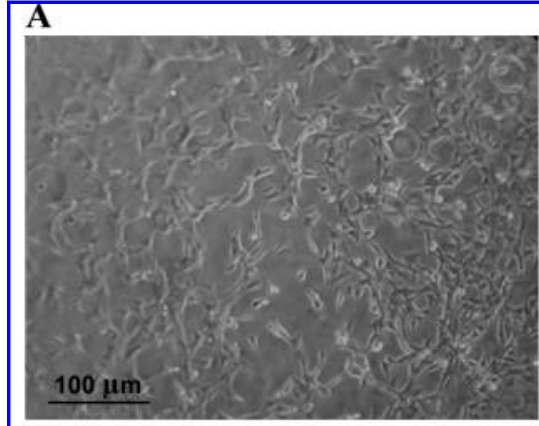

D

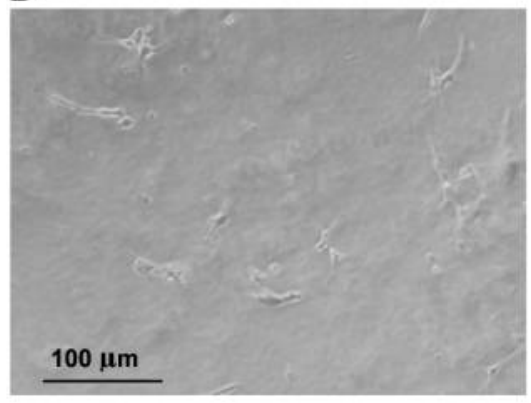

G

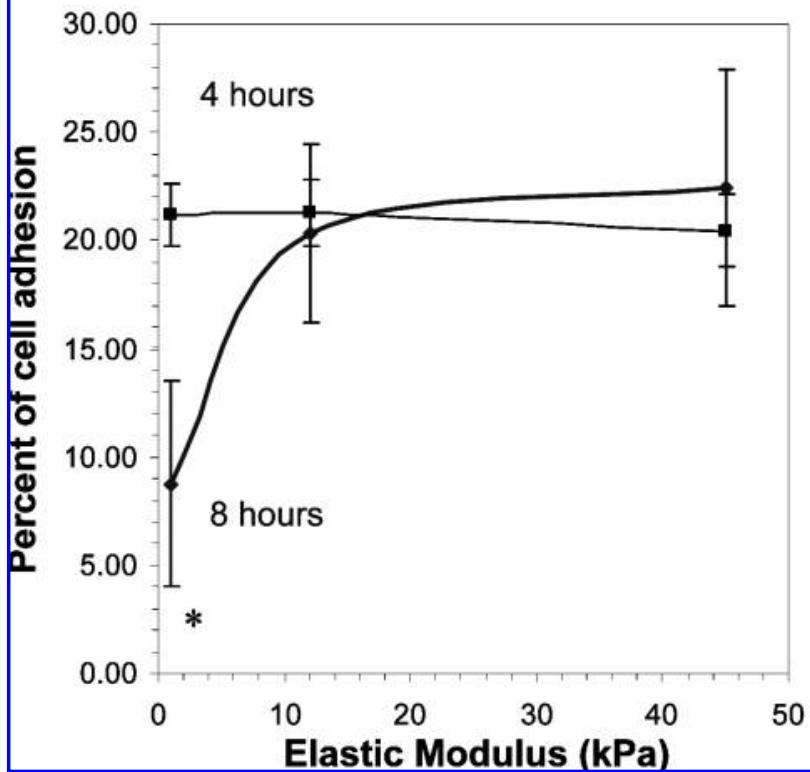

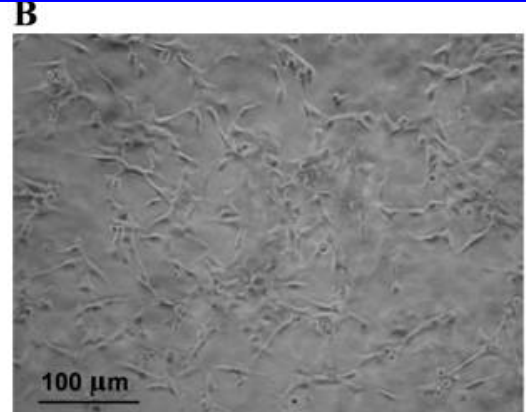

$\mathbf{E}$

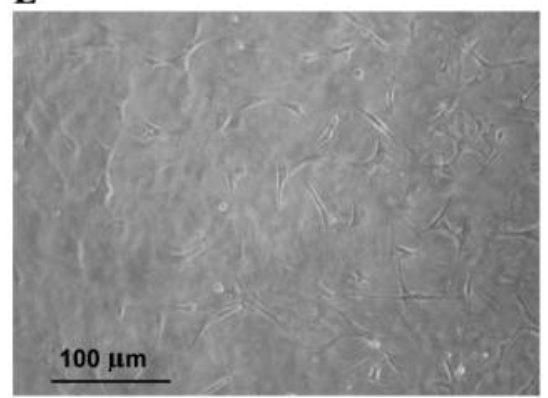

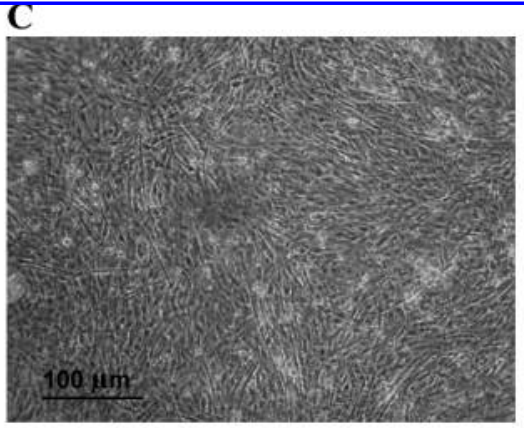

F

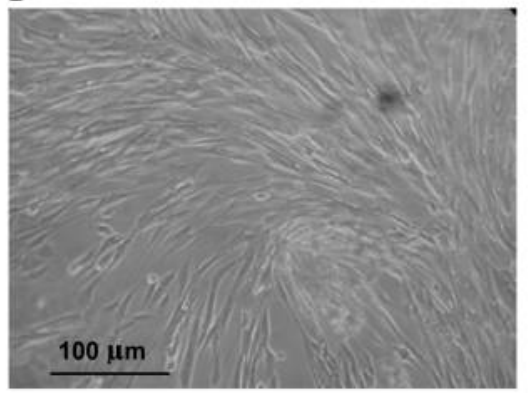

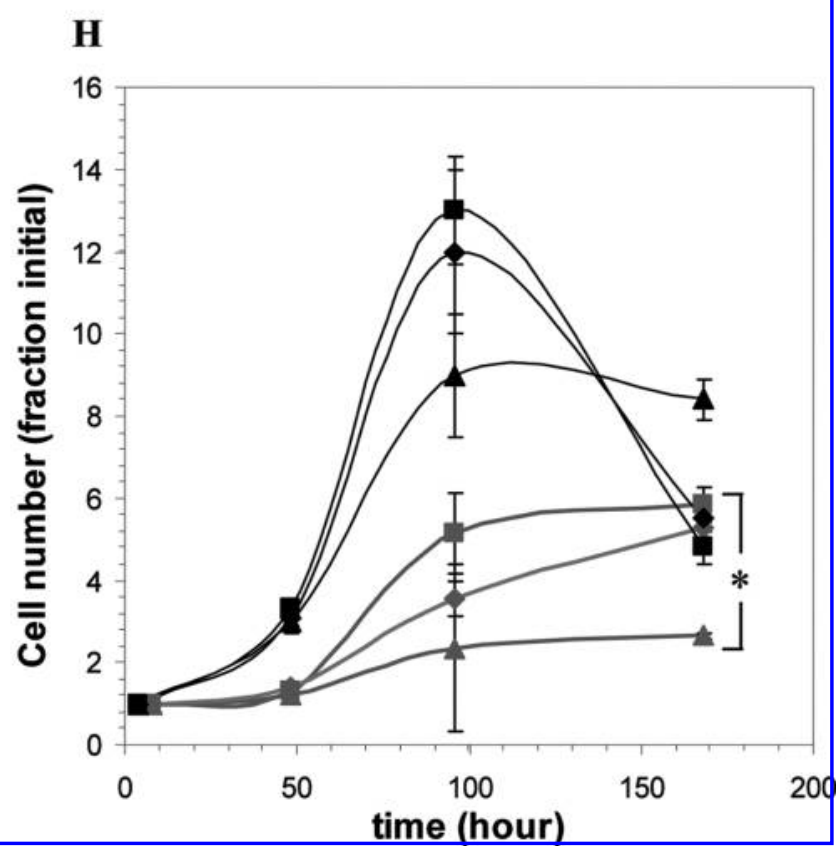

FIG. 2. Influence of substrate compliance on myoblast adhesion and proliferation. Photomicrographs of the $\mathrm{C} 2 \mathrm{C} 12$ cells $(\mathbf{A}-\mathbf{C})$ and mouse primary myoblasts (D-F). The $\mathrm{C} 2 \mathrm{C} 12$ cells adhered similarly on all gels (A,-representative image), but showed limited cell fusion when cultured on the softest gels $(E=1 \mathrm{kPa})(\mathbf{B})$, while they differentiated to form myotubes when $\mathrm{E}=13$ or $45 \mathrm{kPa}(\mathbf{C})$. Mouse primary cells exhibited limited spreading when cultured on gels at $\mathrm{E}=1 \mathrm{kPa}(\mathbf{D})$, but spread and proliferated at $\mathrm{E}=13 \mathrm{kPa}(\mathbf{E})$, and proliferated and fused to form myotubes at $\mathrm{E}=45 \mathrm{kPa}(\mathbf{F})$. Initial $\mathrm{C} 2 \mathrm{C} 12$ adhesion at 4 hours postseeding ( $\mathbf{\square})$ and primary myoblast adhesion at 8 hours postseeding $(\diamond)$ on alginate gels differing in stiffness were determined by direct cell counting, and cell numbers were subsequently normalized to this initial cell density $(\mathbf{G})$. Normalized cell count illustrates proliferation rate of adherent $\mathrm{C} 2 \mathrm{C} 12$ (black) and primary myoblasts (gray) on these three gel types: $\mathrm{E}=1 \mathrm{kPa}(\boldsymbol{\Lambda}), 13 \mathrm{kPa}(\boldsymbol{\bullet})$, and $45 \mathrm{kPa}(\boldsymbol{\square})(\mathbf{H})$. Scale bar in A-F represents $100 \mu \mathrm{m}$. Data are representative of at least two independent experiments and reported as mean $\pm \operatorname{SD}(n=4)$. The difference in cell adhesion between primary cells on the lowest modulus material and those on the stiffer materials was statistically significant $\left({ }^{*} p<0.05\right.$, t-test, $\left.n=4\right)$. The difference in primary cell number among the three conditions at 168 hours was statistically significant $\left({ }^{*} p<0.05\right.$, one-way ANOVA test, $\left.n=4\right)$. The decrease in cell number at 168 hours for $\mathrm{C} 2 \mathrm{C} 12$ cells was caused by cell fusion. 


\section{Effect of substrate stiffness on myoblast phenotype}

$\mathrm{C} 2 \mathrm{C} 12$ cell adhesion was similar when gel stiffness was varied from 1 to $45 \mathrm{kPa}$ (Figs. 2A, G), and once adherent, the cells spread and proliferated. On the softest gel $(\mathrm{E}=1 \mathrm{kPa})$, $\mathrm{C} 2 \mathrm{C} 12$ cells exhibited normal spreading but did not show cell fusion (Fig. 2B). They did fuse to form myotubes when cultured on stiffer gels $(\mathrm{E}=13$ or $45 \mathrm{kPa})$ (Fig. 2C). The proliferation rate of $\mathrm{C} 2 \mathrm{C} 12$ was high and largely independent of gel stiffness (Fig. 2H). The reduction in cell number between day 4 and day 7 correlated to cell fusion into multinucleated cells, not cell death or detachment (Fig. 2H).

In contrast, primary myoblast adhesion and proliferation were regulated by gel stiffness. Primary cells preferentially adhered to stiffer gels $(\mathrm{E}=12$ or $45 \mathrm{kPa}$ ) as compared to more malleable gels $(\mathrm{E}=1 \mathrm{kPa}$ ) (Fig. $2 \mathrm{G}$ ). Primary cells on the most malleable gels exhibited limited spreading (Fig. 2D), and proliferation was dramatically lower than that observed on stiffer gels (Fig. 2H). Primary cells on the stiffer gels elongated and proliferated at a greater rate over time (Fig. $2 \mathrm{E})$. Unlike the $\mathrm{C} 2 \mathrm{C} 12$ cells, there was no reduction in cell number due to myoblast fusion between day 4 and day 7 , as these cells did not reach confluence over the course of the experiments. After day 10, no further cell proliferation, but a slight reduction in cell number, was observed on the softest gels $(E=1 \mathrm{kPa})$, likely due to the limited ability of these cells to spread on this material. On stiffer gels $(E=13$ and $45 \mathrm{kPa}$ ), the primary cells still did not significantly increase in number and reach confluence, which is a prelude to cell fusion and the resultant decrease in cell number. This ap- peared to be due to the limited multiplication ability of the isolated primary cell population after a certain passage number (passage 3-4 after Percoll purification) in the tested media condition. This effect is also noticed during cell cultures on tissue culture polystyrene flasks (TCPS), and required that each experiment be performed with freshly purified mouse primary myoblasts.

Cell differentiation was also regulated by substrate stiffness, and the sensitivity was dependent on the cell type. C2C12 cells exhibited continuously increasing levels of $\mathrm{MCK}$, an enzyme upregulated during late differentiation (Fig. 3A). There was no statistically significant difference between cells on gels with $\mathrm{E}=14$ or $45 \mathrm{kPa}$. MCK activity was significantly lower at $\mathrm{E}=1 \mathrm{kPa}$, which was consistent with the failure of cells to differentiate and form myotubes on these gels. Similar findings were obtained with primary cells, as the stiffest gels $(\mathrm{E}=45 \mathrm{kPa})$ promoted cell differentiation, leading to an increased MCK activity over time (Fig. 3B). On the contrary, cells on softer gels $(E=1$ and $13 \mathrm{kPa}$ ) did not fuse, and MCK activity at both conditions was significantly lower compared to cells on the stiffest gels (Fig. 3B).

\section{C2C12 culture within gels}

$\mathrm{C} 2 \mathrm{C} 12$ cells were next cultured within gels that varied in their degradation rate, instead of on the gels as in the 2-D studies. The rate of cellular proliferation, as measured with ${ }^{3} \mathrm{H}$-thymidine incorporation, was dependent on the degradability of the gels (Fig. 4A). C2C12 proliferation rate was highest in the most slowly degrading and stiffest gels. The
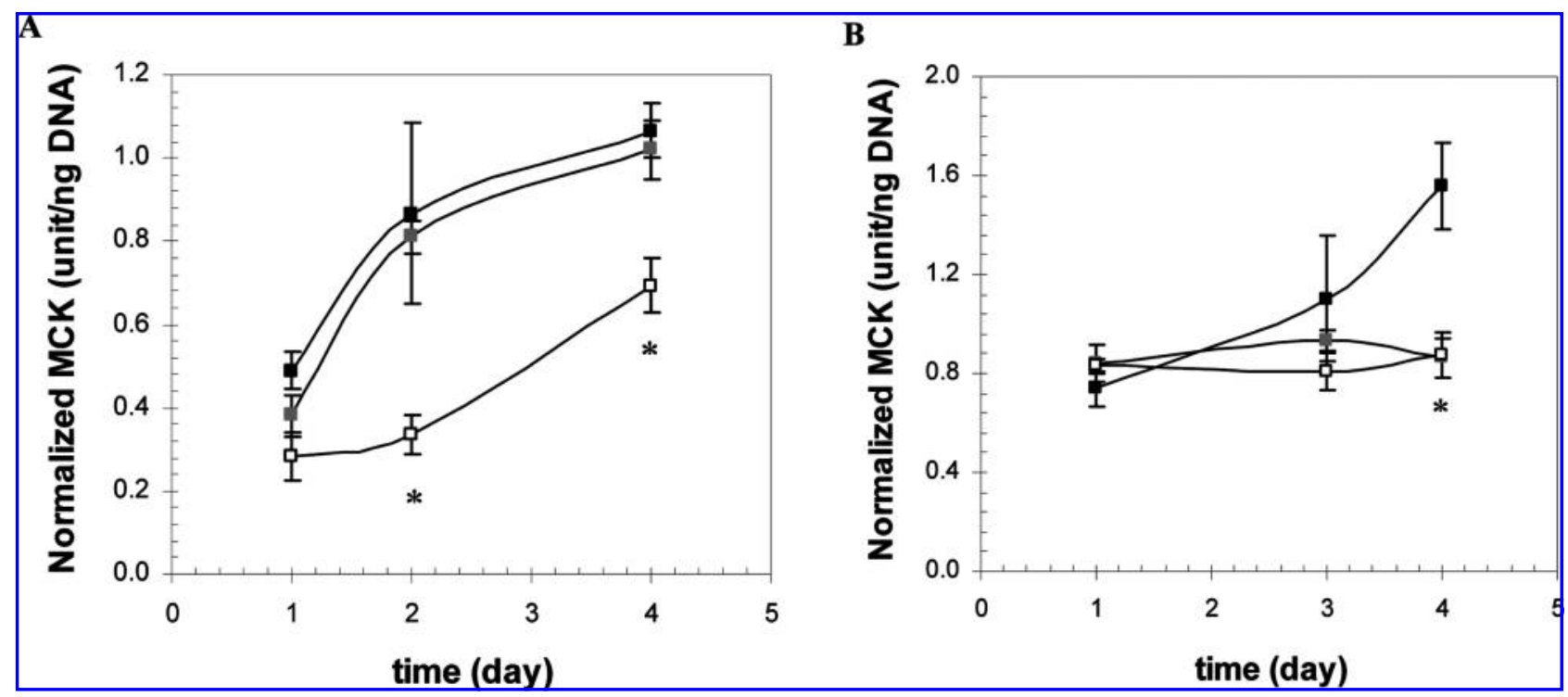

FIG. 3. Effect of substrate stiffness on myoblast differentiation. Normalized MCK activity of C2C12 cells (A) and primary mouse myoblasts (B) on gels varying in stiffness $(\mathrm{E}=1 \mathrm{kPa}(\square), 13 \mathrm{kPa}(\square)$, and $45 \mathrm{kPa}(\boldsymbol{\square})$ ). Values were normalized to DNA amounts collected at each time point. Data are representative of at least two independent experiments and reported as mean $\pm \mathrm{SD}$. The differences in normalized MCK activity of C2C12 cells among the three gels on days 2 and 4 (A), and that of primary myoblasts on day 4 (B), were statistically significant $(* p<0.05$, one-way ANOVA, $n=4)$. 


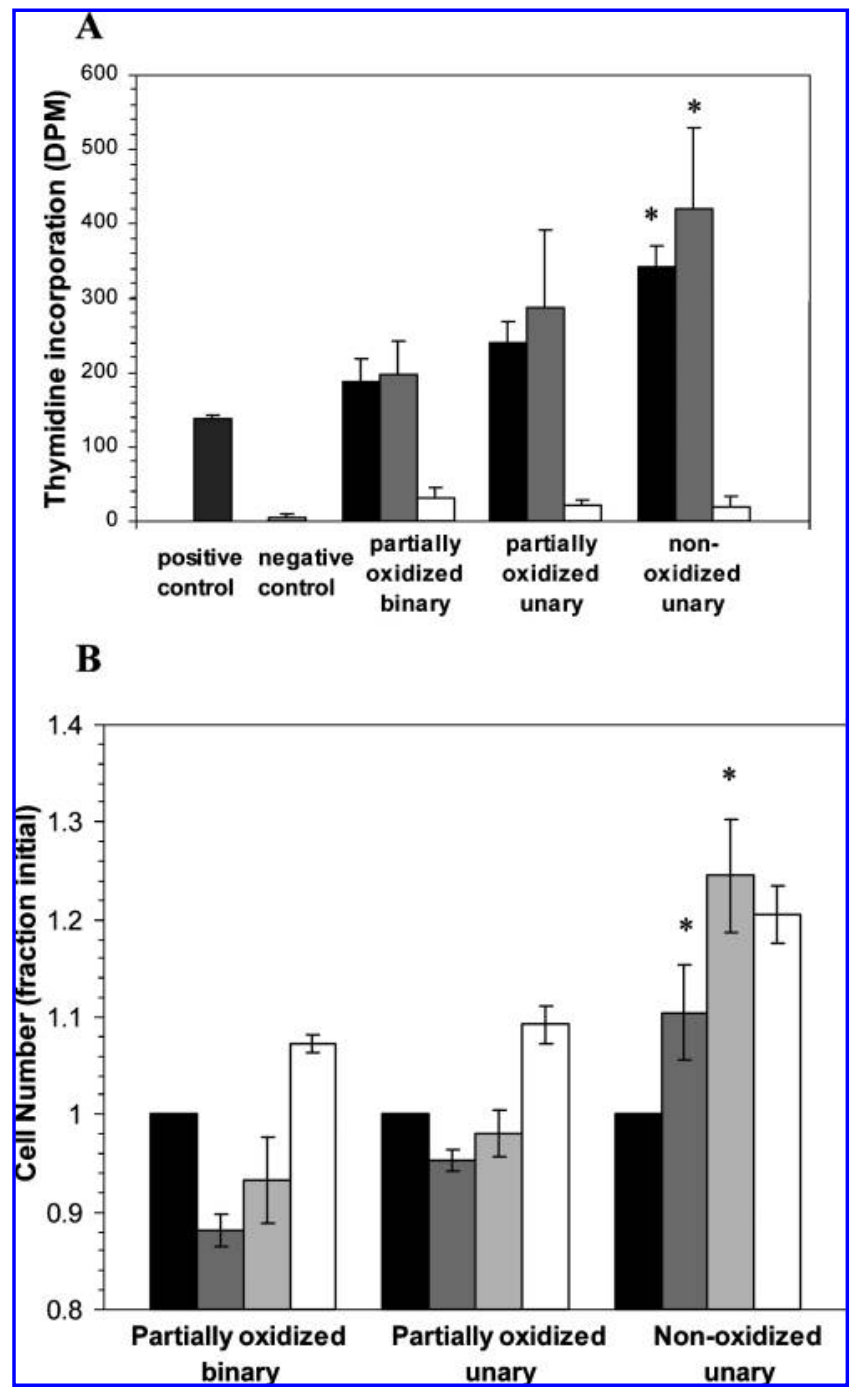

FIG. 4. Effect of gel degradation on $\mathrm{C} 2 \mathrm{C} 12$ proliferation. (A) $\left[{ }^{3} \mathrm{H}\right]$ thymidine incorporation was quantified on days $5(\boldsymbol{\square})$, and $10(\square)$, when gels were cultured in proliferation medium, and on day $15(\square)$, after they were cultured in differentiation medium. A positive control (adherent $\mathrm{C} 2 \mathrm{C} 12$ on 2-D gels) and a negative control (gels without cells) are also shown for comparison. (B) Direct cell counts were obtained on days $1(\square), 5(\square), 10(\square)$, and $15(\square)$ and normalized to the initial number (day 1). Data are representative of at least two independent experiments and reported as mean $\pm \mathrm{SD}$. The differences in values of thymidine incorporation and cell counts among the three gel conditions at each particular time point are statistically significant $(* p<0.05$, one-way ANOVA, $n=6$ ).

reliability of this assay to monitor proliferation was tested by subsequently culturing myoblasts in differentiation medium that arrested proliferation. ${ }^{3} \mathrm{H}$-thymidine incorporation was arrested (Fig. 4A) as myoblasts withdrew from the cell cycle. The thymidine incorporation data was consistent with direct cell counting (Fig 4B), as the cell numbers increased most rapidly in the most slowly degrading gels. Quantification of DNA amounts also illustrated similar findings (data not shown).
Gel degradability also influenced myoblast differentiation. Cells cultured in the degradable gels (partially oxidized binary and unary gels) spread and fused to form multinucleated myotubes (Fig. 5A). On the contrary, cells in the nondegradable gels (nonoxidized unary gel) maintained a round morphology (Fig. 5B), and neither cell spreading nor fusion was observed in these gels. Western blotting for myogenin, a marker for entry of myoblasts into the differentiation pathway, ${ }^{14}$ showed that this transcription factor increased over time from day 5 (Fig. 5C) and its expression in cells encapsulated in degradable gels was higher than in cells within nondegradable gels at all time points. The muscle structural protein MHC, a later-stage muscle-specific gene, ${ }^{13}$ was expressed at detectable levels only in degradable gels on days 12 and 19 (Fig. 5D). No MHC was detected in nondegradable gels. MCK activity increased over time in the cultures (Fig. 5E) and was statistically higher in degradable gels.

\section{Primary cell culture within gels}

The above studies were next repeated with the primary cells, and in contrast to the results for $\mathrm{C} 2 \mathrm{C} 12$ cells, the proliferation rate of primary myoblasts (determined by ${ }^{3} \mathrm{H}-$ thymidine incorporation) was significantly higher in degradable than in nondegradable gels over the entire experimental period (Fig. 6A). Direct cell counting and quantification of DNA amounts led to consistent results, as both were higher over time for cells in the degradable gels compared to cells in the nondegradable gels (Figs. 6B, C). However, the differentiation of primary myoblasts encapsulated within both gel types was quite limited. There was no myogenin expression over the entire culture time, and the low levels of MCK in these cells cultured under these conditions did not noticeably increase over time (data not shown).

\section{DISCUSSION}

The objective of our study was to examine how mechanical stiffness and degradation of scaffolding material regulated the function of myoblasts in 2-D and 3-D cultures. The stiffness of alginate gels controlled $\mathrm{C} 2 \mathrm{C} 12$ cell and primary myoblast phenotype in 2-D culture. Increased stiffness led to higher cell proliferation and differentiation of both cell types, although these effects were more pronounced in primary cells. Adhesion of $\mathrm{C} 2 \mathrm{C} 12$ cells, in contrast to results with primary cells, was unaffected by the range of moduli used. The degradability of the gels also regulated the morphology, proliferation, and differentiation of the two cell types in 3-D culture, although the two cell types had distinct, even opposite responses in this system.

Gel compliance regulated adhesion, proliferation, and differentiation, but the response and sensitivity of myoblasts to this variable was highly dependent on the myoblast source. Cell adhesion, spreading, and proliferation increased with 


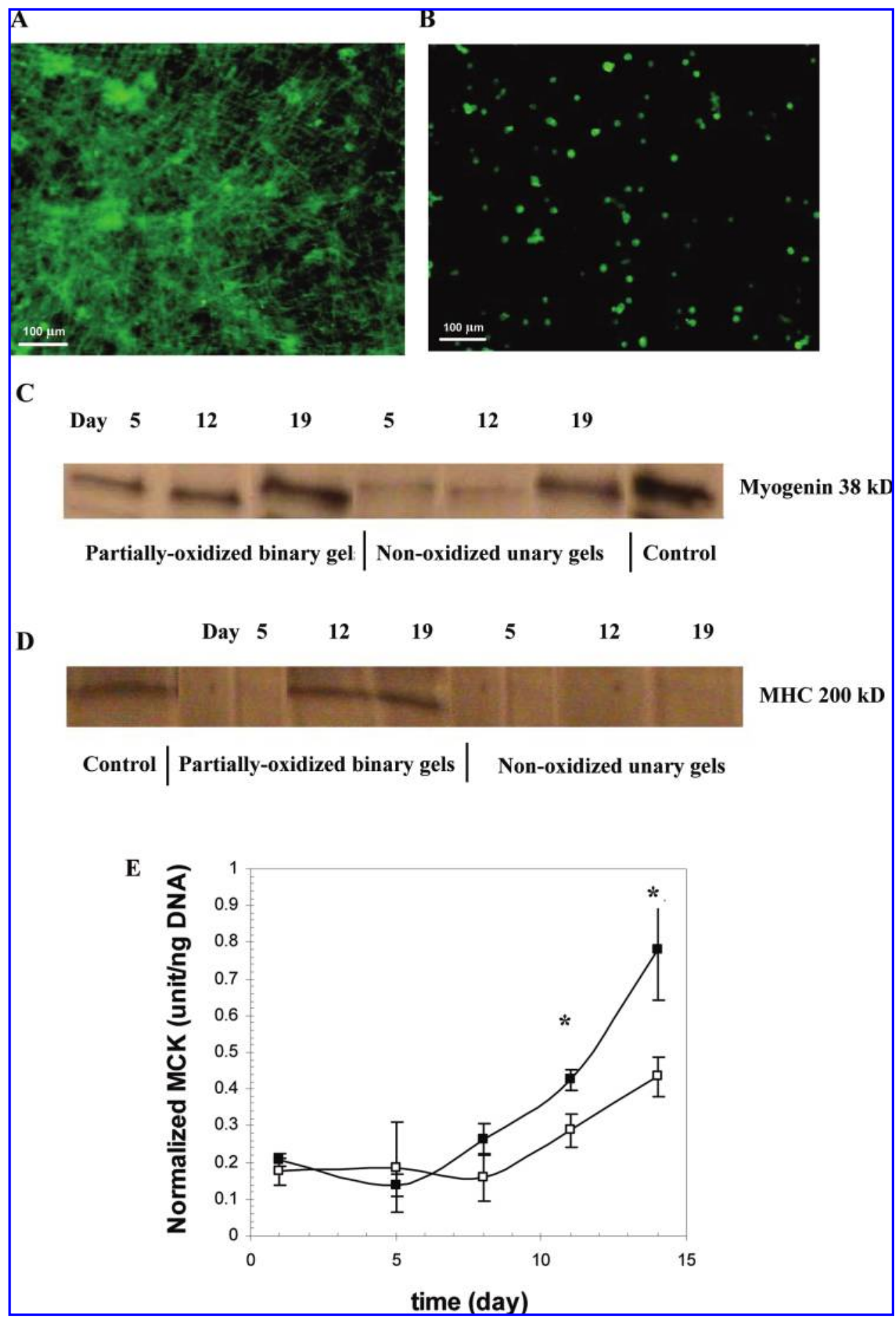

FIG. 5. Effect of gel degradation on $\mathrm{C} 2 \mathrm{C} 12$ differentiation in 3-D culture. Cells fused to form myotubes on day 7 in partially oxidized binary gels (A), but maintained a round shape in nonoxidized unary gels (B) (optical section $100 \mu \mathrm{m}$ from the surface). Western blot analysis on cell extracts from $\mathrm{C} 2 \mathrm{C} 12$ encapsulated in alginate gels for expression of myogenin (C) and MHC (D). Control lanes consisted of lysates from $\mathrm{C} 2 \mathrm{C} 12$ cells cultured in standard 2-D conditions that promoted differentiation. Normalized MCK activity illustrated differentiation rate of $\mathrm{C} 2 \mathrm{C} 12$ encapsulated in partially oxidized binary gels ( $\mathbf{\square}$ ), and nonoxidized unary gels ( $\square$ ) (E). MCK activity was normalized by DNA amount of each sample harvested at each particular time point. Data are reported as mean \pm SD $\left({ }^{*} p<0.05\right.$, t-test, $\left.n=4\right)$. Color images available online at www.liebertpub.com/ten. 


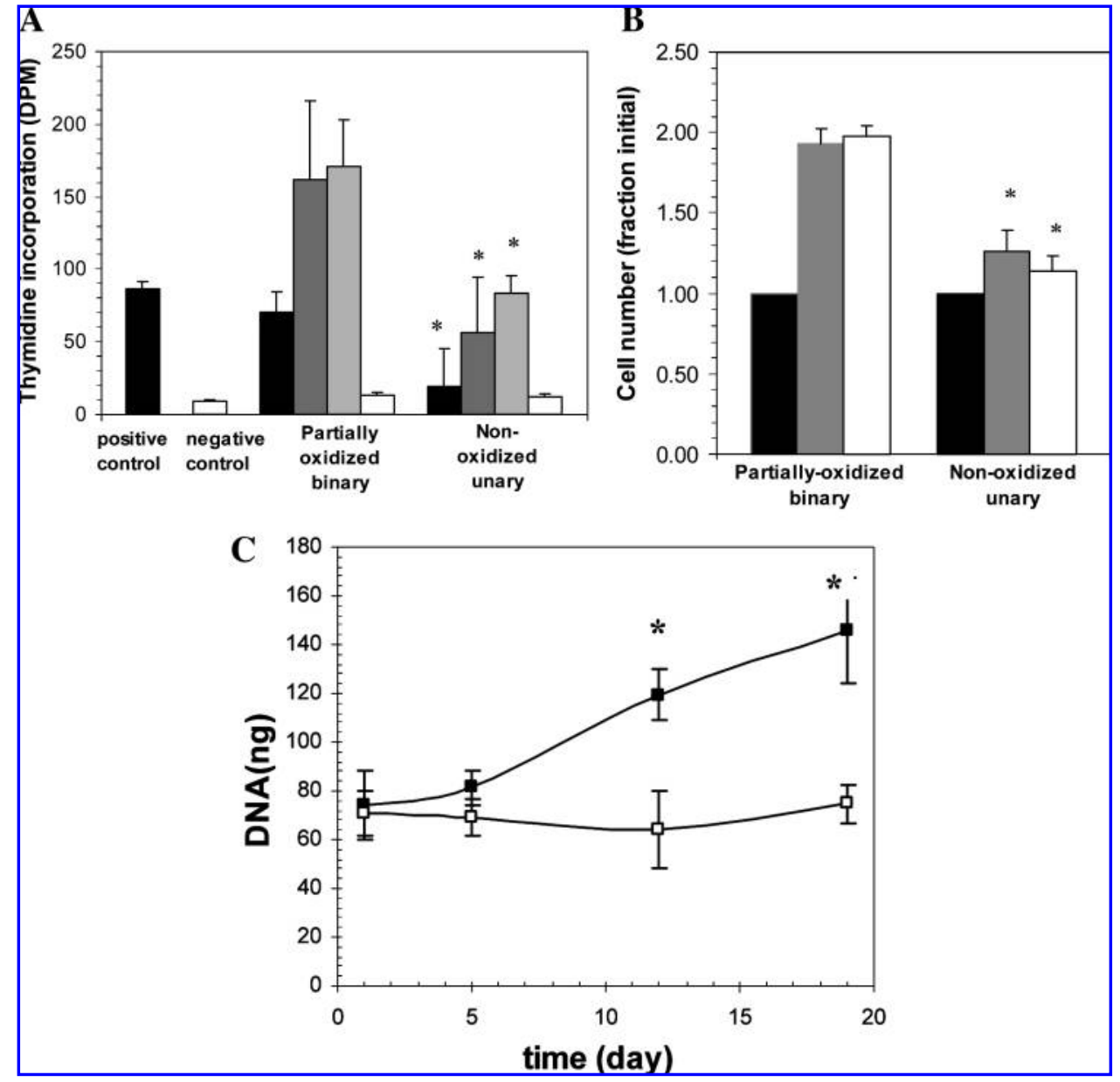

FIG. 6. Effect of gel degradation on primary myoblast proliferation. (A) ${ }^{3} \mathrm{H}$-thymidine incorporation was quantified on days 5 ( $\square$ ), $10(\square)$, and $14(\square)$, when gels were cultured in proliferation medium, and on day $16(\square)$, when gels were cultured in differentiation medium. A positive control (adherent C2C12 on 2-D gels) and a negative control (gels without cells) are also shown for comparison. (B) Direct cell counts were obtained on days $1(\square), 7$ ( $\square$ ), and 14 ( $\square$ ) and normalized to the initial number (day 1). (C) The DNA quantity from primary cells encapsulated in partially oxidized binary gels $(\boldsymbol{\square})$ and nonoxidized unary gels $(\square)$ was also measured over time. Data are representative of at least two independent experiments and reported as mean $\pm \mathrm{SD}$. The differences in values of thymidine incorporation (except at day 16) and in cell counts between the two conditions are statistically significant at each particular time point $(* p<0.05$, t-test, $n=6)$.

substrate stiffness for primary myoblasts, but a moderate to no effect on the $\mathrm{C} 2 \mathrm{C} 12$ cells was noted in 2-D culture. The results with primary cells are generally consistent with past studies proposing that stiffer gels lead to an enhanced cell ability to assemble machinery necessary to generate traction force and drive entry into cell cycle. ${ }^{5}$ However, the current findings differ from a recent study using C2C12 cells cultured on collagen-coated PA gels, ${ }^{4}$ in which cell spreading was found to increase as gel stiffness was increased from 1$17 \mathrm{kPa}$. This disparity may be due to the different gel systems used to regulate the stiffness of the adhesion substrates, or the different adhesion sites (RGD ligands versus collagen) present in the two systems. The RGD ligand may drive continued myoblast proliferation; prior work has demonstrated that degradation of the fibronectin typically presenting the RGD motif in ECM coincides with myoblast withdrawal from the cell cycle and differentiation. ${ }^{32,33}$ The limited differentiation of both cell types on the softer gels, as indicated in this study by little cell fusion and low MCK levels, is consistent with the observations in previous studies with $\mathrm{C} 2 \mathrm{C} 12$ cells on soft PA gels. In any case, the present findings suggest that the $\mathrm{C} 2 \mathrm{C} 12$ cell line may not accurately reflect the response of normal cells to mechanical cues in many situations. Wang et al. demonstrated that rat bone marrow cells exhibited higher proliferation on stiffer gels (high-G alginate gels) than on softer gels (high-M alginate gels). ${ }^{34}$ Although they did not use adhesion signals such as RGD peptides, biomaterials with higher stiffness promoted cell proliferation as observed in the present study. Mechanistically, normal alginate gels degrade via exchange of divalent cross-linking cations with sodium. It is possible that the high-M alginate gels released more calcium ions and 
soluble alginate molecules and these effected cell proliferation. To confirm whether the higher myoblast proliferation noticed in the current study was solely due to substrate stiffness or due to a combined effect with soluble alginate molecules, further experiments involving addition of soluble alginates directly to the media would be useful. Previous studies with these alginate gels have demonstrated that the differences in the amount of calcium released to the media were not statistically significant between nonoxidized and partially oxidized gels. This is because the primary degradation mechanism of this gel system is main-chain scission, not ion exchange, ${ }^{30}$ and this indicates that varying amounts of divalent cation release from the gels is not a major factor in regulating myoblast proliferation.

The degradability of gels was found to regulate myoblast proliferation and differentiation in 3-D culture, although opposite responses were noted with $\mathrm{C} 2 \mathrm{C} 12$ versus primary myoblasts. Rapidly degrading gels led to low $\mathrm{C} 2 \mathrm{C} 12$ proliferation, due to cells exiting the cell cycle, and promoted C2C12 fusion into multinucleated myotubes with heightened expression of myogenin and MHC. On the contrary, $\mathrm{C} 2 \mathrm{C} 12$ cells in nondegradable gels exhibited high proliferation and were unable to withdraw from the cell cycle to differentiate and form myotubes. The dependence of proliferation on gel stiffness was consistent with the 2-D culture results for $\mathrm{C} 2 \mathrm{C} 12$ cells, but the effects on differentiation were distinct from those found in 2-D culture. The differentiation response may be related to the reduction in gel mechanical stiffness during degradation, which could facilitate cell movement through the gels and the cell-cell contact necessary for cell fusion within the 3-D nanoporous structure of the gels. Strikingly, primary myoblasts proliferated more in degrading gels than in nondegradable gels, where there was very little or no cell proliferation. This effect was the opposite of that found with $\mathrm{C} 2 \mathrm{C} 12$ cells. Primary myoblasts did not differentiate significantly in either type of gel, regardless of the gel degradability. This last finding is supported by previous studies that demonstrated that primary myoblasts within macroporous alginate scaffolds expressed MyoD but not myogenin. ${ }^{35}$ The lack of proliferation in the stiff, nondegrading gels is surprising, as the primary cells proliferated extensively when cultured on these gels (2-D culture), but perhaps reflects the inability of these cells to adapt to confinement within a nonmalleable 3-D material. Primary myoblasts maintained a round morphology in both gel types (data not shown), suggesting that spreading and migration of these cells was minimal in the gels. Other studies with different cell types have also indicated that the degradation rate of materials encapsulating cells can regulate cell phenotype and tissue formation in vitro and in vivo. ${ }^{8-10}$

The results of these studies indicate that cellular responses to materials can be dramatically different between 2-D and 3-D cultures, suggesting that results from typical 2-D culture have limited ability to predict cell response in 3-D culture. In 2-D culture, C2C12 proliferation was insensitive to the stiffness of the adhesion substrate, and differentiation in- creased with substrate stiffness. In contrast, in 3-D culture they exhibited greater proliferation in stiffer gels and differentiation was greatest in the softer, degrading gels. Both primary myoblast proliferation and differentiation increased with the stiffness of the adhesion substrate in 2-D culture, while proliferation was low in stiffer, nondegrading gels in 3 -D culture and the cells exhibited minimal differentiation in either type of gel. The lack of correlation between the two culture systems has been suggested to reflect unnatural geometric and mechanical cues in 2-D culture that create an imbalance between cell spreading and retraction. ${ }^{36}$ However, specific conclusions cannot be drawn from the results of the current studies because mechanical properties changed with time in the degrading gels, making it unclear whether the cells were responding to gel mechanical properties, gel dissolution, or both. However, as 3-D culture in degradable analogs of the ECM mimics physiologically relevant tissue structure more closely than 2-D culture, studies in 3-D culture may provide better clues to implement biomaterial design in vivo.

\section{CONCLUSIONS}

The results from this study directly support the effect of mechanical compliance and degradability of cell culture materials on the phenotype of skeletal muscle cells. Increasing the gel stiffness raised primary myoblast adhesion, proliferation, and differentiation in a standard 2-D culture system, as anticipated, but influenced $\mathrm{C} 2 \mathrm{C} 12$ phenotype to a lesser degree. Importantly, when cells were cultured in 3D, slowly degrading gels enhanced $\mathrm{C} 2 \mathrm{C} 12$ proliferation, while rapidly degrading gels promoted their differentiation, perhaps due to a reduction in mechanical stiffness during degradation, which facilitated the cell-cell contact necessary for cell fusion and exiting from the cell cycle. In contrast, primary cells proliferated more extensively in the rapidly degrading gels and did not differentiate significantly in either type of gel. Thus, the phenotype of cells in 3D culture may be temporally regulated by regulating both the initial mechanical properties and their rate of change over time. The results also indicate that one must be cautious in generalizing results obtained with cell lines to more physiologically relevant processes (e.g., tissue regeneration), as significantly different or even opposing results may be obtained for primary cells. Both of these conclusions should be considered in the design of tissue engineering and regeneration strategies for various tissues.

\section{ACKNOWLEDGMENTS}

The authors would like to thank NIDCR/NIH for financial support (R01 DE13349), as well as the Royal King Anandamahidol foundation (Thailand) for a graduate fellowship to Tanyarut Boontheekul. 


\section{REFERENCES}

1. Lutolf, M.P., and Hubbell, J.A. Synthetic biomaterials as instructive extracellular microenvironments for morphogenesis in tissue engineering. Nat Biotechnol 23, 47, 2005.

2. Ingber, D.E., Dike, L., Hansen, L., Karp, S., Liley, H., Maniotis, A., McNamee, H., Mooney, D., Plopper, G., Sims, J., and Wang, N. Cellular tensegrity: exploring how mechanical changes in the cytoskeleton regulate cell growth, migration, and tissue pattern during morphogenesis. Int Rev Cytol 150, 173, 1994.

3. Beningo, K.A., and Wang, Y.L. Flexible substrata for the detection of cellular traction forces. Trends Cell Biol 12, 79, 2002.

4. Engler, A.J., Griffin, M.A., Sen, S., Bonnemann, C.G., Sweeney, H.L., and Discher, D.E. Myotubes differentiate optimally on substrates with tissue-like stiffness: pathological implications for soft or stiff microenvironments. $\underline{\mathrm{J} \text { Cell Biol }}$ 166, 877, 2004.

5. Kong, H.J., Polte, T.R., Alsberg, E., and Mooney, D.J. FRET measurements of cell-traction forces and nano-scale clustering of adhesion ligands varied by substrate stiffness. Proc Natl Acad Sci USA 102, 4300, 2005.

6. Romer, L.H., Birukov, K.G., and Garcia, J.G. Focal adhesions: paradigm for a signaling nexus. Circ Res 98, 606, 2006.

7. Lu, L., Zhu, X., Valenzuela, R.G., Currier, B.L., and Yaszemski, M.J. Biodegradable polymer scaffolds for cartilage tissue engineering. Clin Orthop Relat Res 391S, S251, 2001.

8. Alsberg, E., Kong, H.J., Hirano, Y., Smith, M.K., Albeiruti, A., and Mooney, D.J. Regulating bone formation via controlled scaffold degradation. J Dent Res 82, 903, 2003.

9. Bryant, S.J., and Anseth, K.S. Hydrogel properties influence ECM production by chondrocytes photoencapsulated in poly (ethylene glycol) hydrogels. J Biomed Mater Res 59, 63, 2002.

10. Bryant, S.J., and Anseth, K.S. Controlling the spatial distribution of ECM components in degradable PEG hydrogels for tissue engineering cartilage. J Biomed Mater Res A 64A, 70, 2003.

11. Bach, A.D., Beier, J.P., Stern-Staeter, J., and Horch, R.E. Skeletal muscle tissue engineering. J Cell Mol Med 8, 413, 2004.

12. Grounds, M.D., White, J.D., Rosenthal, N., and Bogoyevitch, M.A. The role of stem cells in skeletal and cardiac muscle repair. J Histochem Cytochem 50, 589, 2002.

13. Charge, S.B., and Rudnicki, M.A. Cellular and molecular regulation of muscle regeneration. Physiol Rev 84, 209, 2004.

14. Andres, V., and Walsh, K. Myogenin expression, cell cycle withdrawal, and phenotypic differentiation are temporally separable events that precede cell fusion upon myogenesis. J Cell Biol 132, 657, 1996.

15. Miller, K.J., Thaloor, D., Matteson, S., and Pavlath, G.K. Hepatocyte growth factor affects satellite cell activation and differentiation in regenerating skeletal muscle. Am J Physiol Cell Physiol 278, C174, 2000.

16. Dean, D.A. Non viral gene transfer to skeletal, smooth, and cardiac muscle in living animals. Am J Physiol Cell Physiol 289, C233, 2005.

17. Beauchamp, J.R., Morgan, J.E., Pagel, C.N., and Partridge, T.A. Dynamics of myoblast transplantation reveal a discrete minority of precursors with stem cell-like properties as the myogenic source. J Cell Biol 144, 1113, 1999.
18. Powell, C.A., Smiley, B.L., Mills, J., and Vandenburgh, H.H. Mechanical stimulation improves tissue-engineered human skeletal muscle. Am J Physiol Cell Physiol 283, C1557, 2002.

19. Huang, Y.C., Dennis, R.G., Larkin, L., and Baar, K. Rapid formation of functional muscle in vitro using fibrin gels. $\underline{\mathrm{J} \text { Appl }}$ Physiol 98, 706, 2005.

20. Pedrotty, D.M., Koh, J., Davis, B.H., Taylor, D.A., Wolf, P., and Niklason, L.E. Engineering skeletal myoblasts: roles of three-dimensional culture and electrical stimulation. Am J Physiol Heart Circ Physiol 288, 1620, 2005.

21. Hill, E., Boontheekul, T., and Mooney, D.J. Regulating activation of transplanted cells controls tissue regeneration. Proc Natl Acad Sci USA 103, 2494, 2006.

22. Smidrod, O., and Skjåk-Bræk, G. Alginate as immobilization matrix for cells. TIBTECH 8, 71, 1990.

23. Zimmermann, H., Zimmermann, D., Reuss, R., Feilen, P.J., Manz, B., Katsen, A., Weber, M., Ihmig, F.R., Ehrhart, F., Gessner, P., Behringer, M., Steinbach, A., Wegner, L.H., Sukhorukov, V.L., Vasquez, J.A., Schneider, S., Weber, M.M., Volke, F., Wolf, R., and Zimmermann, U. Towards a medically approved technology for alginate-based microcapsules allowing long-term immunoisolated transplantation. $\underline{\mathrm{J} \text { Mater Sci Mater }}$ Med 16, 491, 2005.

24. Shen, F., Li, A.A., Gong, Y.K., Somers, S., Potter, M.A., Winnik, F.M., and Chang, P.L. Encapsulation of recombinant cells with a novel magnetized alginate for magnetic resonance imaging. Hum Gene Ther 16, 971, 2005.

25. Alsberg, E., Anderson, K.W., Albeiruti, A., Rowley, J.A., and Mooney, D.J. Engineering growing tissues. Proc Natl Acad Sci USA 99, 12025, 2002.

26. Rowley, J.A., Madlambayan, G., and Mooney, D.J. Alginate hydrogels as synthetic extracellular matrix materials. Biomaterials 20, 45, 1999.

27. Bouhadir, K.H., Lee, K.Y., Alsberg, E., Damm, K.L., Anderson, K.W., and Mooney, D.J. Degradation of partially oxidized alginate and its potential application for tissue engineering. Biotechnol Prog 17, 945, 2001.

28. Kong, H.J., Lee, K.Y., and Mooney, D.J. Decoupling the dependence of rheological/mechanical properties of hydrogels from solids concentration. Polymer 43, 6239, 2002.

29. Kong, H.J., Kaigler, D., Kim, K., and Mooney, D.J. Controlling rigidity and degradation of alginate hydrogels via molecular weight distribution. Biomacromolecules 5, 1720, 2004.

30. Boontheekul, T., Kong, H.J., and Mooney, D.J. Controlling alginate gel degradation utilizing partial oxidation and bimodal molecular weight distribution. Biomaterials 26, 2455, 2005.

31. Sjoberg, G., Jiang, W.Q., Ringertz, N.R., Lendahl, U., and Sejersen, T. Colocalization of nestin and vimentin/desmin in skeletal muscle cells demonstrated by three-dimensional fluorescence digital imaging microscopy. Exp Cell Res 214, 447, 1994.

32. Dourdin, N., Brustis, J.J., Balcerzak, D., Elamrani, N., Poussard, S., Cottin, P., and Ducastaing, A. Myoblast fusion requires fibronectin degradation by exteriorized m-calpain. Exp Cell Res 235, 385, 1997.

33. Gullberg, D., Sjoberg, G., Velling, T., and Sejersen, T. Analysis of fibronectin and vitronectin receptors on human fetal skeletal muscle cells upon differentiation. Exp Cell Res 220, 112, 1995. 
34. Wang, L., Shelton, R.M., Cooper, P.R., Lawson, M., Triffitt, J.T., and Barralet, J.E. Evaluation of sodium alginate for bone marrow cell tissue engineering. Biomaterials 24, 3475, 2003.

35. Hill, E., Boontheekul, T., and Mooney, D.J. Designing scaffolds to enhance transplanted myoblast survival and migration. Tissue Eng 12, 1295, 2006.

36. Birgersdotter, A., Sandberg, R., and Ernberg, I. Gene expression perturbation in vitro - a growing case for threedimensional (3D) culture systems. Semin Cancer Biol 15, 405, 2005.
Address reprint requests to: David J. Mooney, Ph.D. Division of Engineering and Applied Sciences Harvard University 29 Oxford St. Pierce Hall Room 325 Cambridge, MA 02138

E-mail: mooneyd@deas.harvard.edu 


\section{This article has been cited by:}

1. Alastair Khodabukus, Keith Baar . Regulating Fibrinolysis to Engineer Skeletal Muscle from the C2C12 Cell LineRegulating Fibrinolysis to Engineer Skeletal Muscle from the C2C12 Cell Line. Tissue Engineering Part C: Methods, ahead of print. [Abstract] [PDF] [PDF Plus]

2. Cathy Chu, John J. Schmidt, Kay Carnes, Zhen Zhang, Hyun Joon Kong, Marie-Claude Hofmann . 2009. Three-Dimensional Synthetic Niche Components to Control Germ Cell ProliferationThree-Dimensional Synthetic Niche Components to Control Germ Cell Proliferation. Tissue Engineering Part A 15:2, 255-262. [Abstract] [PDF] [PDF Plus] [Supplementary material]

3. Merel Koning, Martin C. Harmsen, Marja J. A. van Luyn, Paul M. N. Werker. 2009. Current opportunities and challenges in skeletal muscle tissue engineering. Journal of Tissue Engineering and Regenerative Medicine n/a-n/a. [CrossRef]

4. Matthew S. O'Connor, Morgan E. Carlson, Irina M. Conboy. 2009. Differentiation rather than aging of muscle stem cells abolishes their telomerase activity. Biotechnology Progress NA-NA. [CrossRef]

5. Kristel J.M. Boonen , Mark J. Post . 2008. The Muscle Stem Cell Niche: Regulation of Satellite Cells During RegenerationThe Muscle Stem Cell Niche: Regulation of Satellite Cells During Regeneration. Tissue Engineering Part B: Reviews 14:4, 419-431. [Abstract] [PDF] [PDF Plus]

6. Giancarlo Forte, Felicia Carotenuto, Francesca Pagliari, Stefania Pagliari, Paolo Cossa, Roberta Fiaccavento, Arti Ahluwalia, Giovanni Vozzi, Bruna Vinci, Annalucia Serafino, Antonio Rinaldi, Enrico Traversa, Luciana Carosella, Marilena Minieri, Paolo Di Nardo. 2008. Criticality of the Biological and Physical Stimuli Array Inducing Resident Cardiac Stem Cell Determination. Stem Cells 26:8, 2093-2103. [CrossRef] 